\title{
LOCAL COMPOSITIONS AND THERMODYNAMICS OF POLAR/NON-POLAR MIXTURES
}

\author{
$S W$. de Leeuw, \\ Laboratorium voor Fysische Cheme, Nieuwe Achtergracht 127, 1018 wS Amsterdam. The \\ Netherlands, \\ and \\ $C P$ Willams and $B$ Smit, \\ Konmklijke/Shell-Laboratorium, Amsterdam. (Shell Research B V.), P.O. Box 3003, 1003 AA \\ Amsterdam, The Netherlands
}

(Received November 28, 1988)

\section{ABSTRACT}

de Leeuw, SW, Willıams, C P and Smit, B, 1988 Local compositions and thermodynamics of polar/non-polar mixtures

Results of computer simulations are presented for the thermodynamic properties of mixing and the local compositions for mixtures of Stockmayer and Lennard-Jones flusds with varying concentrations and dipole strengths The results show a strong asymmetry with respect to the concentration which is attributed to the influence of the orientation dependence of the dipoledipole interaction and explained in terms of a "frustration" effect

\section{INTRODUCTION}

The concept of local compositions, which describes the deviations of concentrations withın a region around a specific particle from the overall bulk concentratıons, and the importance of such deviations for liquid models, can be traced back as far as the work of Rushbrooke (1938) and Guggenheim (1944) Recently there has been renewed Interest in these Ideas primarly motivated by efforts to extend the applicability of equations of state to include the liquid-phase description of non-ıdeal mixtures through the use of fundamental mixing rules Methods have been proposed (Mollerup, 1981, Whitıng and Prausnit2, 1982, LI et al, 1986) by which the local composition mixıng rules may be combined with an equation of state

By using computer simulations it has become possible to determine the local composition of well defined model systems and to use these data for further improvement of the local composition models Previously, computer sımulatıons have been concerned mainily with the local,composition of particles with isotropic potentials The results of these earlier studies suggested that the local compositions and phase behaviour were highly symmetric with respect to the bulk concentration This is in direct contrast with experimental observations for polarinon-polar mixtures

Mixtures of Lennard-Jones and Stockmayer partıcles provide a convenient model system which can be used to sludy the microscopic behaviour of polar/non-polar mixtures with computer simulation lechniques Furthermore the simulations also allow the calculation of the thermodynamic properties of mixıng for these theorelical fluid mixtures

\section{COMPUTATIONAL DETAILS}

The energy of interaction between two Stockmayer molecules with dipole moments $\vec{\mu}_{1}$ and $\vec{\mu}_{2}$ separaled by a distance $r_{12}$ is given by 
$\phi_{\mathrm{S}}\left(\vec{\mu}_{1}, \vec{\mu}_{2}, \vec{r}_{12}\right)=-\frac{\vec{\mu}^{2}}{\vec{r}_{12}{ }^{3}} D(1.2)+\phi_{L J}\left(\vec{r}_{12}\right)$

where

$D(1,2)=3\left(\hat{\mu}_{1} \cdot \hat{r}_{12}\right)\left(\hat{i}_{2} \cdot \hat{r}_{12}\right)-\hat{i}_{1} \cdot \hat{\mu}_{2}$

where denotes the unit vector $D(1,2)$ is the angular dependence of the dipolar interaction and $\phi_{i v}$ is the usual Lennard-Jones interaction

$\phi_{L J}(r)=4 \varepsilon\left\{\left[\frac{\sigma}{r}\right]^{12}-\left[\frac{\sigma}{r}\right]^{8}\right\}$

In the work reported here we have studied fluid mixtures of Stockmayer and LennardJones molecules in which the size parameter, $\sigma$, and the energy parameter, $\varepsilon$, of the Stockmayer molecules are identical to those of the Lennard-Jones molecules Deviations from ideal mixing in these systems are therefore due entırely to the polarity of the Stockmayer molecules and allows us to siudy the effect of polarify and composition on the microscopic structure and the thermodynamic properties of these mixtures

Isothermal-isochoric molecular dynamics (MD) calculations have been performed for mixlures with various mole fractions, $x_{5}$, of Stockmayer molecules The temperature was held constant with a Nose thermostat (Nose, 1384) using a Nose mass of 100 in reduced units

The simulations were performed at a reduced lemperalure of $T^{*}=k T / s=115$ and a reduced density of $p^{*}==f r^{3}=0822$ Both the pure Lennard-Jones and the pure Stockmayer fluids have been studied exlensively at this state point previously (Adams and Adams, 1981, Neumann et al 1984, Petersen et al, 1988) The reduced dipole moment, $H^{*}-\mu / \delta \sigma^{-}$was vared between 00 and 20 , covering a range of physically realistic values The long-range dipolar interactions were handled with slandard Ewald summation techniques using 'tinfoll' boundary condilions (de Leeuw et al, 1986) A total of 309 reciprocal lattice vectors were used for the evaluation of the Fourier part of the Ewald summation The value of $\alpha$. the parameter which governs the convergence of the two series in the Ewatd sum, was set to 658

The simulalions were carried out for a lotal of $N=108$ particles A. few runs were performed with a larger number of particles to study the $\mathrm{N}$-dependence of the results The total energy was found to be almost independent of the number of particles and for the pressure a slight dependence (a few percent) was observed

In the simulations. the system was equilibrated for at least 5000 time-steps and followed by a production run of at least 15,000 trme-steps A time-step of $00025 \tau$ was used, where $\tau$ is the reduced unit of time defined as $\tau=\sqrt{m^{2} / r}$ 


\section{RESULTS}

\subsection{Thermodynamic Properties}

In table I we have collected the values of the potential energy obtained from our sımulatıons for varıous compositions and dipolar strengths The contributions due to the LennardJones interactions, including the long-tail correction, have also been included These contributions are seen to increase with dipolar strength and mole fraction $x_{s}$ of the Stockmayer molecules This is of course expected due to the tendency of the dipolar interactions to decrease the distance of closest approach which in turn increases the contribution of the repulsive energy in the Lennard-Jones potential

\begin{tabular}{|c|c|c|c|c|c|c|c|}
\hline & \multicolumn{7}{|c|}{ Fraction of Stockmayer particles, $x_{s}$} \\
\hline$\mu^{\cdot 2}$ & 0000 & 0167 & 0333 & 0500 & 0.667 & 0833 & 1000 \\
\hline 050 & 5526 & 5518 & 5589 & 5599 & 5658 & 5749 & 5825 \\
& & 5503 & 5548 & 5503 & 5498 & 5515 & 5510 \\
100 & 5526 & 5585 & 5679 & 5831 & 6026 & 6219 & 6451 \\
& & 5551 & 5517 & 5523 & 5526 & 5481 & 5469 \\
1.50 & 5526 & 5630 & 6845 & 6125 & 6453 & 6822 & 7223 \\
& & 5526 & 5514 & 5501 & 5478 & 5458 & 5426 \\
225 & 5526 & 5756 & 6188 & 6683 & 7259 & 7866 & 8517 \\
& & 5528 & 5484 & 5463 & 5413 & 5355 & 5331 \\
300 & 5526 & 5986 & 6606 & 7331 & 8136 & 9049 & 9920 \\
& & 5490 & 5432 & 5383 & 5326 & 5253 & 5194 \\
4.00 & 5526 & 6274 & 7302 & 8.364 & 9.510 & 10724 & 12039 \\
& & 5450 & 5353 & 5278 & 5181 & 5070 & 4975 \\
\hline
\end{tabular}

TABLE I Polential energy - $U /\left(N_{\varepsilon}\right)$ for mixtures of Lennard-Jones and Slockmayer fluids for varıous compositions $x_{S}$ and reduced dipolar strengths $\mu^{* 2}$ (The lower number is the contribution of $L J$ Interactions )

The excess energy of mixıng $U_{e x}$ can be readily obtaıned Irom the data in table I In figure 1 the variation of $U_{\mathrm{ex}}$ with composition is shown for three different values of the reduced dipolar strength $\mu^{* 2}$ As expected $U_{e x}$ increases with increasing reduced dipolar strength, however the most interesting feature of the figure is the asymmetric behaviour of $U_{\text {ex }}$ with respect to the composition The energy of mixing has a maxımum at mole fractions $x_{S}$ slighly less than $0.5, \mathrm{i} e$ at compositıons rich in the non-polar component This corresponds with what has been observed experimentally in a number of polarinon-polar mixtures such as $\mathrm{CH}_{3} \mathrm{OH} / \mathrm{C}_{6} \mathrm{H}_{6}$ and $\mathrm{C}_{2} \mathrm{H}_{5} \mathrm{OH} / \mathrm{C}_{6} \mathrm{H}_{14}$ (KIng, 1969, pp 27-35)

The asymmetric behaviour has also been observed in the variation of the excess free energy of mixing $f_{\text {ex, }}$ as shown elsewhere (de Leeuw et al, 1988) For values of $\mu^{* 2}>4$ it was shown that this leads to a phase separation into an almost pure Lennard-Jones fluid and a Stockmayer-rich phase This agrees with the results of Morriss and Isbister (1986) who solved the sıte-site Ornsteın-Zernıcke equatıon, usıng the mean spherical approxımation closure, for mixtures of polar and non-polar hard-dumbbelis 
It is instructive to compare our results with those of Wong and Johnsion (1984) who performed Monte Carlo simulations of strongly non-ideal liquid mixtures The dipolar interactions were included in the form of an angle-averaged expression and the behaviour of the excess properties with respect to the composition was found to be highly symmetric This comparison demonstrates that it is indeed the orientation dependence of the dipolar interactions that is responsible for the asymmetry in the composition dependence of $U_{\text {ex }}$ and $f_{\text {ex }} A$ similar asymmetric behaviour is observed for the local composition as a function of the mole fraction of Stockmayer molecules which is discussed in the foliowing section

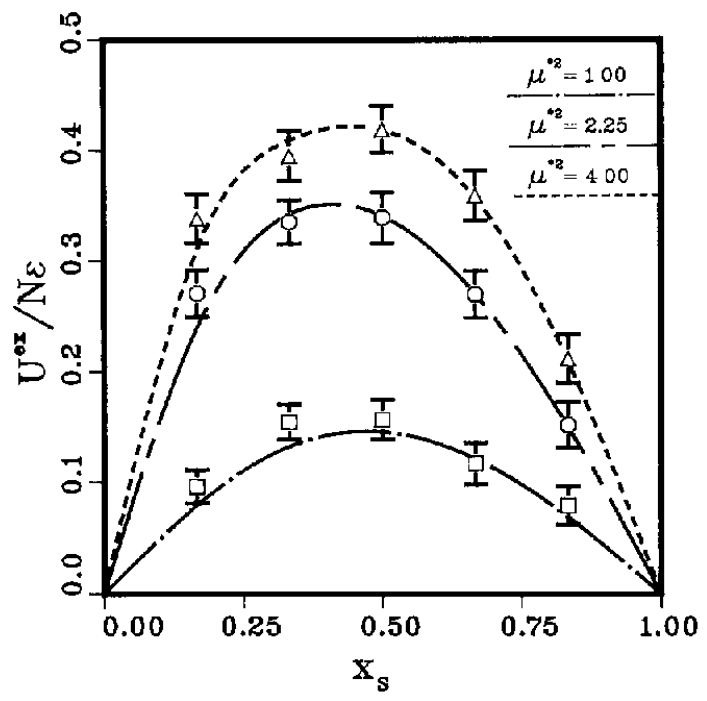

Fig 1 Excess energy of mixing $U_{e v} / N r$ versus concentration $x_{S}$

In lable II values for the compressibility factor $(Z=P V / N k T)$ are given for the various compositions and reduced dipole moments Again we observe deviations from idealıty which behave asymmetrically with respect to the composition

\subsection{Local Composition}

The Iocal composition in mixtures of square-well fluids has been thoroughly examıned in a series of papers by Lee and Sandler and their co-workers $(1984,1986 \mathrm{a}, 1986 \mathrm{~b}, 1987)$ The use of square-well lluids is advantageous in that the cut-off distance in the integrations for the calculation of the local mole fraction is unambiguously delined Furthermore the properlies of such fluid mixtures are claimed to resemble mixtures of Lennard-Jones molecules

The local composition of equmolar, equal-sızed Lennard-Jones mixtures have themselves been studied previouly (Nakanıshı and Toukubo, 1979. Nakanıshı and Tanaka. 1983. Nakanıshı et al 1983) usıng molecular dynamics and by Wong and Johnston (1984) usıng Monte Carlo simulations In both studies a variety of combinıng rules were used for the energy parameter 


\begin{tabular}{|l|l|l|l|l|l|l|l|}
\hline & \multicolumn{6}{|c|}{ Fraction of Stockmayer particles, $x_{s}$} \\
\hline$\mu^{* 2}$ & 0000 & 0167 & 0333 & 0500 & 0667 & 0833 & 1000 \\
\hline 050 & 22 & 24 & 21 & 23 & 22 & 21 & 21 \\
100 & 22 & 21 & 22 & 20 & 18 & 19 & 17 \\
150 & 22 & 22 & 20 & 18 & 17 & 14 & 12 \\
225 & 22 & 21 & 19 & 15 & 13 & 10 & 05 \\
300 & 22 & 20 & 17 & 13 & 09 & 04 & -01 \\
400 & 22 & 19 & 15 & 09 & 03 & -03 & -10 \\
\hline
\end{tabular}

TABLE | Compressiblity factor PV/NkT for mixtures of Lennard-Jones and Stockmayer fluids for varıous compositions $x_{S}$ and reduced dipolar strengths $\mu^{* 2}$

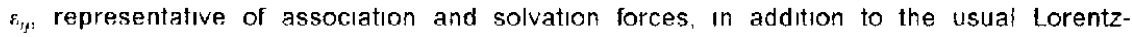
Berthelot (L-B) geometric mean typical of dispersive-only forces

The local composition of Lennard-Jones mixtures with differing component sizes, obeying the L-B mixing rules, has been studied using molecular dynamics (Gierycz and Nakanishi. 1984, Gierycz et al, 1984) Hoheisel and Kohler (1984) investigated the local composition in L-B mixtures of Lennard-Jones fluids with both equal and differently sized particles Lee et al (1986) studied the effects of size and energy differences in both Lennard-dones and Kinara mixtures These studies concluded that packing effects, and not the attractive forces, are the dominant cause of non-randomness in liquid mixtures obeyıng the L-B combining rules

The number of I-particles around a central f-particle, withın a given distance $L$, is rigorously defined in terms of the distribution function $g_{i}(r)$ (Lee et al, 1983) and is given by

$N_{1,}(L)=x_{i} \int_{0}^{L} d r g_{i j}(r)$

and similarly for f-particles around a central J-particle

$N_{j J}(L)=x_{j} p \int_{0}^{L} d r g_{j j}(r)$

For a binary mixture the local mole fractions may then be defıned according to the following

$X_{1 j}(L)=\frac{N_{1 j}(L)}{\left(N_{1 j}(L)+N_{j j}(L)\right)}$

with the condition that

$x_{1 j}(L)+x_{y l}(L)=10$ 
Obviously for contunuous interaction potentials the actual value of $X_{1}(L)$ depends on the choice of $L$, the cut-off point for the integrations This is typically chosen to correspond with the end of the first-coordination shell and, as pornted out by Hoheisel and Kohler (1984), should be independent of the type of contact so as to fulfill the requirement that as $L$ becomes large

$x_{21} \rightarrow x_{2}$

$x_{12} \rightarrow x_{1}$

In this paper we are more concerned with the trends in the local mole fractions rather than the specific values, however for comparison we have chosen $L / \sigma=135$ in keeping with prevous work (Hoheisel and Kohler, 1984)

The lacal mole fractions $x_{i j}$, defined by equations $(3-5)$, have been determined for the simulations discussed earlier the results for $x_{s,}$ and $x_{i t}$ for two of the Stockmayer/Lennard-jones flud mixlures studied are shown in figure $2(a, b)$, for the same three values of the reduced dipole moment shown in frgure 1 The values of $X_{S L}(L / \sigma=135)$ and $X_{L S}(L / \sigma=135)$ for all mixtures and dipole moments are given in tabie III

\begin{tabular}{|c|c|c|c|c|c|}
\hline & \multicolumn{5}{|c|}{ Fraction of Stockmayer Particles, $x_{s}$} \\
\hline$\mu^{* 2}$ & 0167 & $\begin{array}{l}0333 \\
3\end{array}$ & 0500 & (0) 667 & 0833 \\
\hline 050 & $\begin{array}{l}01673 \\
08419\end{array}$ & $\begin{array}{l}0.3315 \\
06632\end{array}$ & $\begin{array}{l}05046 \\
05041\end{array}$ & $\begin{array}{l}06773 \\
03393\end{array}$ & $\begin{array}{l}08312 \\
01661\end{array}$ \\
\hline 100 & $\begin{array}{l}0+664 \\
08365\end{array}$ & $\begin{array}{l}03205 \\
06418\end{array}$ & $\begin{array}{ll}0 & 4980 \\
0 & 4994\end{array}$ & $\begin{array}{ll}0 & 6606 \\
0 & 3311\end{array}$ & $\begin{array}{l}08285 \\
01654\end{array}$ \\
\hline 150 & $\begin{array}{l}01614 \\
0 \quad 8056\end{array}$ & $\begin{array}{l}03151 \\
06274\end{array}$ & $\begin{array}{l}04917 \\
\cap 4917\end{array}$ & $\begin{array}{l}06611 \\
03315\end{array}$ & \begin{tabular}{ll|}
0 & 8221 \\
0 & 1652
\end{tabular} \\
\hline 225 & $\begin{array}{l}01629 \\
08103\end{array}$ & $\begin{array}{l}0.3055 \\
06113\end{array}$ & $\begin{array}{l}04716 \\
0.4707\end{array}$ & 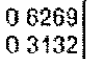 & $\begin{array}{l}08294 \\
01670\end{array}$ \\
\hline 300 & $\begin{array}{l}01392 \\
06893\end{array}$ & $\begin{array}{l}02910 \\
05860\end{array}$ & $\begin{array}{l}04692 \\
04717\end{array}$ & $\begin{array}{l}06550 \\
03319\end{array}$ & $\begin{array}{l}07728 \\
0.1550\end{array}$ \\
\hline 400 & 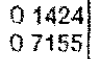 & $\begin{array}{l}02875 \\
05798\end{array}$ & $\begin{array}{l}0.4476 \\
0\end{array}$ & $\begin{array}{l}06171 \\
03134\end{array}$ & 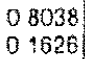 \\
\hline
\end{tabular}

TABLE 111 Local mole fractions $X_{5 L}$ (upper) and $X_{L S}$ (lower) at $L / \sigma=135$ for each composition $x_{3}$ and reduced dipole moment $\|^{2}$

The results are also presented in the form used by Lee and Sandler (Lee and Sandler. 1987), who suggested using the ratio 
LOCAL MOLE FRACTMONS
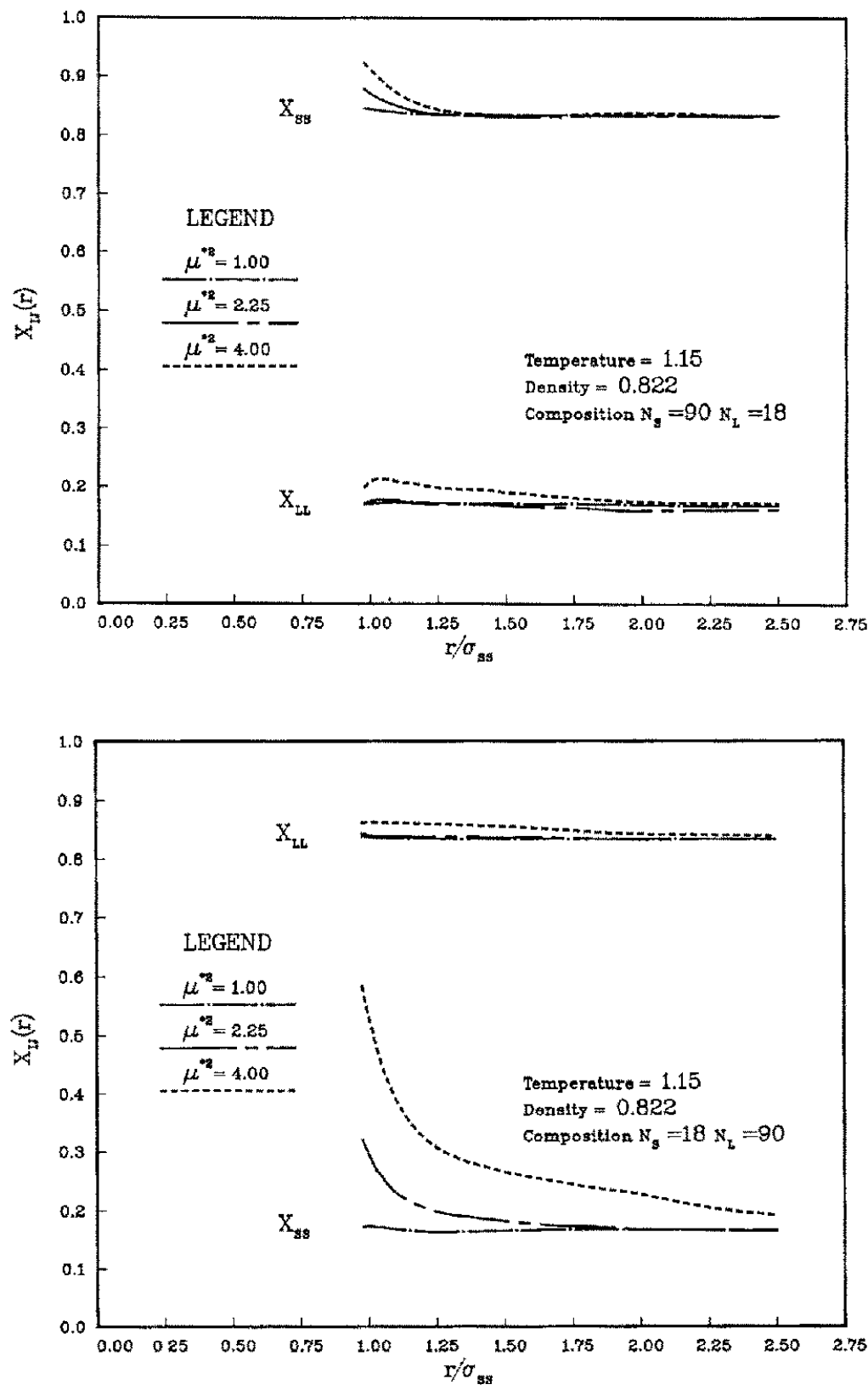

FlG 2 ab Local mole fractions $X_{s s}$ and $X_{4 L}$ for two compositions $x_{5}(0167$ and 0833$)$ and three reduced dipole moments $\mu^{* 2}(1.00,225,400)$ 
$\frac{N_{i} x_{1}}{N_{j i} x_{1}}$

which, if equal to unity would indicate a completely random solution These results are shown in figure $3(a, b)$ and given in table IV (again at $L / \sigma=135$ ) for all mixtures considered

The most notable feature of these results is the asymmetry with respect to the composition, as seen previously, with the greatest deviation from a random solution being found for mixtures with low concentrations of Stackmayer particles As discussed above, this is in agreement with our earlier work (de Leeuw et al, 1988)

\begin{tabular}{|l|c|c|c|c|c|}
\hline & \multicolumn{6}{|c|}{ Fraction of Stockmayer Particles, $x_{5}$} \\
\hline$\mu^{*}$ & 0167 & 0333 & 0500 & 0667 & 0833 \\
\hline 050 & 10046 & 09916 & 10185 & 10496 & 09847 \\
& 10653 & 09847 & 10164 & 10270 & 09961 \\
100 & 09984 & 09433 & 09920 & 09732 & 09662 \\
& 10230 & 08958 & 09975 & 09900 & 09911 \\
150 & 09623 & 09199 & 09674 & 09754 & 09243 \\
& 08286 & 08418 & 09674 & 09918 & 09895 \\
225 & 09727 & 08799 & 08923 & 08401 & 09724 \\
& 08543 & 07863 & 08893 & 0919 & 10023 \\
300 & 08085 & 08208 & 08839 & 09491 & 06801 \\
& 04437 & 07077 & 08927 & 09934 & 09171 \\
400 & 08300 & 08071 & 08104 & 08057 & 08195 \\
& 05030 & 06898 & 08317 & 09130 & 09707 \\
& & & & & \\
\hline
\end{tabular}

TAELE IV Local composition ratios $N_{S L} x_{L} / N_{t !} x_{S}$ (upper) and $N_{i, 5} x_{S,} i N_{S S} x_{L}$ (lower) at $L i \sigma=1.35$ for each composition $x_{S}$ and reduced dipole moment $i^{*}$

Wong and Johnston (1984) also reported values for the local mole fractions for nonpolar!"polar-lıke" mixtures similar to their observatıons concerning the thermodynamic properties of mixing discussed previouly, they found that the local compositions of the systems were symmetric with respect to the bulk concentration This again reinforces our suggesion that the orientation-dependence of the dipole-dipole interaction plays an important role in determining the behaviour of this type of system

\section{DISCUSSION}

It is interesting to speculate about the origin of the asymmetric behaviour shown in the results given above If onc considers two Stockmayer particles within close proximity of each other, in a background of Lennard-Jones particles, then the two polar particles are free to orientate themselves in the most energelically favourable orientation for dipolar particles this occurs when the two are aligned "nose-to-tall" However, increasing the overall concentration of Stockmayer particles increases the probability of a third polar particle also being in the vicinity One can then Imagine that the particles are frustrated in their attempts to achieve this optımal orientation for each pair-Intcraction Therefore some compromise must be achreved 
LOCAL COMPOSITION RATIOS
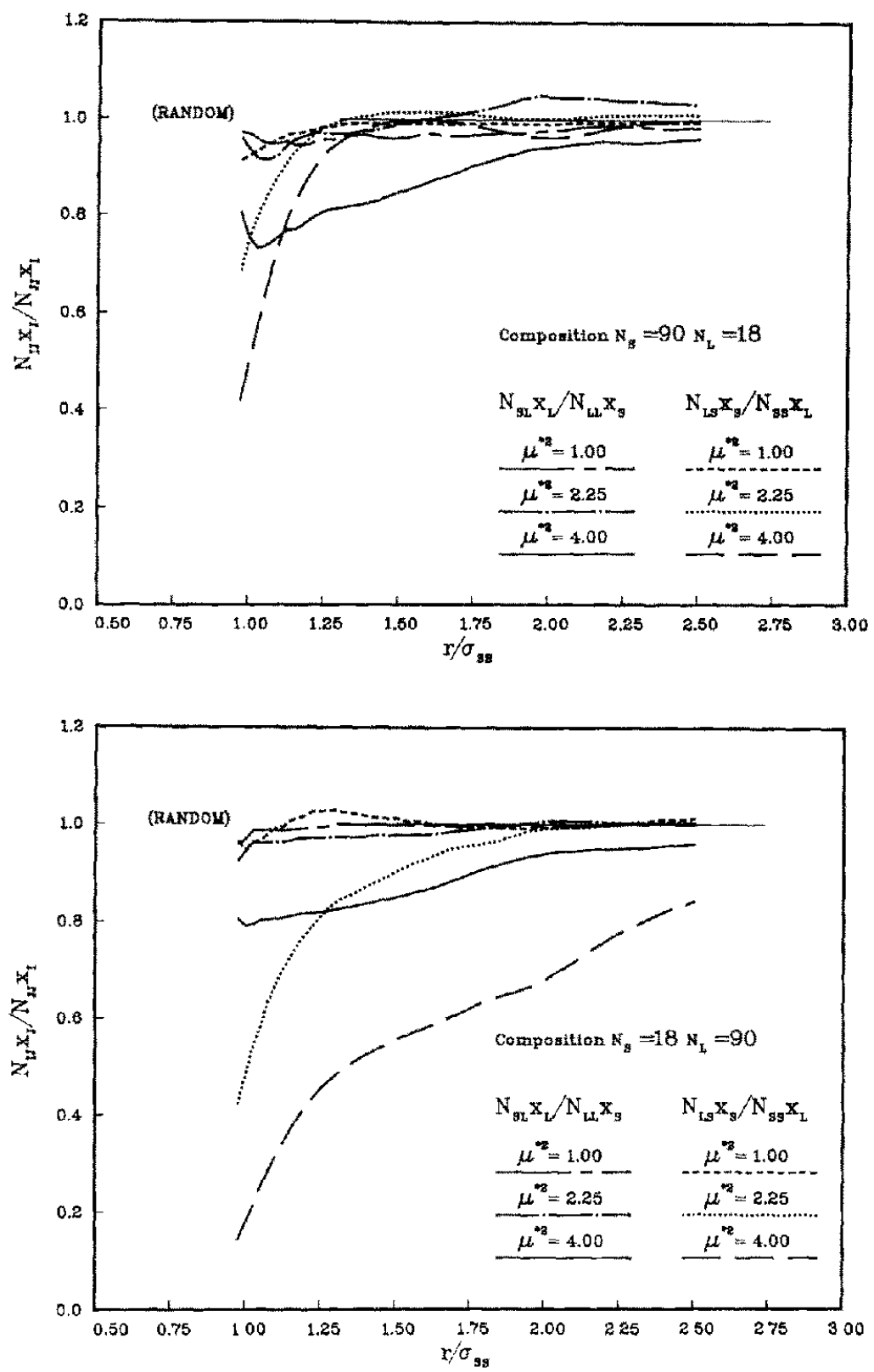

FIG 3 a,b Local composttion ratios $N_{S i} x_{L} \mid N_{L i} x_{S}$ and $N_{L S} ; N_{S 5} x_{L}$ for two compositions $x_{S}(0167$ and $0.833\}$ and throe reduced dipole moments $1.2700,225$ and 400$\}$ 
which will then result in a decrease in the interaction between each pair This arguement is then the basis for our explanation of the observed asymmetry of the results, with respect to the concentration, in terms of our so-called "frustration effect" This suggestion is further reinforced by the orientation correlation functions for these mixtures which will appear elsewhere shortly

\section{Acknowledgements}

We would itke to thank $D$ Frenkel and J Drexhage for helpful discussions concerning the interpretation of the results $S d L$ acknowledges SARA for the allocation of computing time on the IBM-3090-180 at the University of Amsterdam

\section{REFERENCES}

Adams, D J and Adams, EM, 1981 Molec Phys, 42, 907

Gierycz, P, Tanaka, H and Nakanıshı, K, 1984 Fluid Phase Equilibria, 16, 241

Gierycz, P, and Nakanıshi, K, 1984 Flud Phase Equitbria, 16, 255

Guggenheım, E A. 1944 Proc Roy Soc (London) Ser A, 183, 203

Hohessel, C and Kohler, F, 1984 Fluıd Phase Equllibria, 16, 13

Kıng, M B , 1969 Phase Equilibrium In Liquid Mixtures Pergamon press, Oxford, 27-35

Lee, $\mathrm{K}-\mathrm{H}$ and Sandler, SI, 1987 Fluid Phase Equilioria, 34, 113

Lee, K-H, Lombardo. M and Sandier, S1. 1985 Fluid Phase Equilibria, 17, 217

Lee, K-H, Sandler, SI and Monson, PA, 1986a int J Thermophys : 7, 367

Lee, K-H, Sandler, SI and Patel, NC, 1986b Fluid Phase Equilibria, 25, 31

Lee, L L, Chung, FTH and Starlıng, KE. 1983 Flud Phase Equilibria, 12, 105

Lee, L L, Chung, FTH and Landis LH 1986 Fluid Phase Equilibria, 31, 253

de Leeuw, SW, Perram, JW and Smith, ER, 1986 Ann Rev Phys Chem, 37, 245

de Leeuw, SW, Willams, C P and Smit. B, 1988 Molec Phys, 65, 1269

LI, MH, Chung, F TH, So, C-K, Lee, L L and Staring KE, 1986

ACS Symposium Series No $300, \mathrm{KC}$ Chao and R L Robinson, Ed,

American Chemical Society, Washington D C. pp 250-280

Mollerup, J, 1981 Fluid Phase Equlıbria, 7, 121

Morriss, GP and isbister, D J, 1986 Molec Phys, 59, 911

Nakamsh, $K$ and Toukubo, K, $1979 \mathrm{~J}$ Chem Phys, 70, 5848

Nakanıshı, K. and Tanaka, H, 1983 Flud Phase Equilibria, 13, 371

Nakanıshı, K, Okazakı, S. Ikarı, K Hıguchı, T and Tanaka, H, $1983 \mathrm{~J}$ Chem Phys, 76, 629

Neumann, M, Steınhauser, O and Pawley, GS. 1984 Molec Phys, 52. 97

Nose, S, 1984 Molec Phys, 52, 255 
Petersen, HG, de Leeuw, SW and Perram, JW, 1988 Molec Phys (in press)

Rushbrooke, G S., 1938 Proc Roy Soc (London) Ser A, 166, 296

Whiting, W B and Prausnitz, J M , 1982 Flu:d Phase Equilibria, 9, 119

Wong, JM and Johnston, KP, 1984 , Ind Eng Chem Fundam, 23, 320. 